Article

\title{
Contextualising Urban Experimentation: Analysing the Utopiastadt Campus Case with the Theory of Strategic Action Fields
}

\author{
Matthias Wanner ${ }^{1,2, *}$, Boris Bachmann ${ }^{3}$ and Timo von Wirth 4 \\ ${ }^{1}$ Division Sustainable Consumption and Production, Wuppertal Institute for Climate, Environment and Energy, \\ 42103 Wuppertal, Germany; E-Mail: matthias.wanner@wupperinst.org \\ 2 Faculty of Sustainability, Leuphana University Lüneburg, 21335 Lüneburg, Germany \\ ${ }^{3}$ Centre for Transformation Research and Sustainability (transzent), University of Wuppertal, 42103 Wuppertal, Germany; \\ E-Mail: b.bachmann@uni-wuppertal.de \\ ${ }^{4}$ Dutch Research Institute for Transitions (DRIFT), Erasmus School of Social and Behavioral Sciences, Erasmus University \\ Rotterdam, 3062 PA Rotterdam, The Netherlands; E-Mail: vonwirth@drift.eur.nl
}

* Corresponding author

Submitted: 4 September 2020 | Accepted: 4 December 2020 | Published: 26 March 2021

\begin{abstract}
Practices of urban experimentation are currently seen as a promising approach to making planning processes more collaborative and adaptive. The practices develop not only in the context of ideal-type concepts of urban experiments and urban labs but also organically in specific governance contexts. We present such an organic case in the city of Wuppertal, Germany, centred around a so-called change-maker initiative, 'Utopiastadt.' This initiative joined forces with the city administration and collaborated with a private property owner and the local economic development agency in an unusual planning process for the development of a central brownfield site. Ultimately, the consortium jointly published a framework concept that picked up the vision of the 'Utopiastadt Campus' as an open-ended catalyst area for pilot projects and experiments on sustainability and city development. The concept was adopted by the city council and Utopiastadt purchased more than $50 \%$ of the land. In order to analyse the wider governance context and power struggles, we apply the social-constructivist theory of Strategic Action Fields (SAFs). We focused on the phases of contention and settlement, the shift in interaction forms, the role of an area development board as an internal governance unit and the influences of proximate fields, strategic action, and state facilitation on the development. We aim to demonstrate the potential of the theory of SAFs to understand a long-term urban development process and how an episode of experimentation evolved within this process. We discuss the theory's shortcomings and reflect critically on whether the process contributed to strengthening collaborative and experimental approaches in the governance of city development.
\end{abstract}

\section{Keywords}

collaborative planning; governance experiment; participatory city-making; theory of Strategic Action Fields; urban change; urban experimentation

\section{Issue}

This article is part of the issue "Urban Planning by Experiment" edited by Christian Scholl (Maastricht University, The Netherlands) and Joop de Kraker (Maastricht University, The Netherlands).

(C) 2021 by the authors; licensee Cogitatio (Lisbon, Portugal). This article is licensed under a Creative Commons Attribution 4.0 International License (CC BY).

\section{Introduction}

Over the last three decades, the call for participatory, citizen-centred, communicative, and collaborative urban planning and development has been persistent and clear (Forester, 1999; Healey, 1997; Innes, 1995; JPI Urban Europe, 2019; UN, 2016; WBGU, 2016). Despite this, participatory forms of urban planning are still contested and challenging in practice, and are subject to debate in urban research (Åström, 2020; 
Staffans, Kahila-Tani, \& Kyttä, 2020). More recently, innovation in urban planning has been conceptualised around the notion of experimental urban governance (Bulkeley \& Castán Broto, 2013; Bulkeley et al., 2019). This notion resonates strongly with debates within urban transition theory, which frames urban experimentation as a productive approach to fostering local transformations towards sustainable urban environments (Kronsell \& Mukhtar-Landgren, 2018; Nevens, Frantzeskaki, Gorissen, \& Loorbach, 2013; Sengers, Wieczorek, \& Raven, 2016; von Wirth, Fuenfschilling, Frantzeskaki, \& Coenen, 2018; Voytenko, McCormick, Evans, \& Schliwa, 2016). Experimentation becomes a more prominent activity as it develops as an element of alternative niche activities and is often organised by bottom-up civil society initiatives (Seyfang \& Haxeltine, 2012). These 'new urban actors' demonstrate novel and often informal deliberative processes and alternative planning processes and governance procedures (Willinger, 2014). Bulkeley and Castán Broto (2013, p. 365) see experimental processes as vital for creating such niches which-importantly-"can...challenge regime dominance." Bernstein and Hoffmann (2018) state that there is no shared understanding of such experimental governance, but all approaches share "the notion that something new is being tried out-there is a conscious intervention that differs from the status quo." Evans, Karvonen, and Raven (2016) differentiate urban experimentation from conventional urban development by its explicit emphasis on learning from realworld interventions. This view is shared by Scholl and Kemp (2016), who develop the idea of so-called city labs as suitable hybrid organisational platforms to co-create and steer urban experiments in a multi-stakeholder and multi-disciplinary setting.

In this study, we present a case in the city of Wuppertal, Germany, that - at first sight-ticks the boxes of an ideal-type urban planning experiment centred around a so-called change-maker initiative, 'Utopiastadt.' This bottom-up initiative for co-creative and sustainable city development joined forces with the city administration and collaborated with a private property owner and the local economic development agency in an unusual planning process for the development of a central brownfield site of almost 6 ha in size along an abandoned railway line at Mirke station. Ultimately, the consortium, which was institutionalised as the Utopiastadt Campus Area Development Board (UCAB), jointly published a medium-term framework concept for the development of the area in accordance with Utopiastadt ideals. Instead of aiming for a conventional industrial or housing development, the framework concept picked up the vision of the 'Utopiastadt Campus' as an open-ended catalyst area for pilot projects and experiments on sustainability and city development. The concept was adopted by the city council. Finally, Utopiastadt managed to purchase more than $50 \%$ of the land for further participatory city development.
Looking at the case more closely, it becomes obvious that analysing only the experimental planning phase and its direct outputs poses the risk of overlooking the broader governance context from a long-term perspective. In this light, the round table created through the establishment of the UCAB was far more an attempt to mediate a latent conflict that emerged between Utopiastadt and the property owner than an intentional and jointly agreed experimental planning process or a planned city lab platform. Nevertheless, the real-world process encompasses actors' behavioural and structural deviations from their normal routines, new modes of communication and mutual learning. As Torrens, Schot, Raven, and Johnstone (2019) state, urban experimentation is rarely a linear, structured endeavour; more often, experimental settings emerge organically and are the result of struggles in their specific contexts. Healey (2004, p. 88) defined such settings as "episodes of experimentation," in which new forms of governance are tested and potentially inform and transform the status quo governance processes and cultures. In her work on collaborative planning, she calls for a socialconstructivist and institutional perspective on governance, in which planning is a specific style of governance (Healey, 2006, p. 218). We posit that these institutionalised and socially constructed governance settings should be taken into account in order to understand embedded episodes of experimentation andfurthermore-for the actors and mainstream governance culture to learn from them.

We operationalise the overall governance setting of the Utopiastadt Campus with the help of the theory of Strategic Action Fields (SAFs; Fligstein \& McAdam, 2011, $2012 / 2015)$, which offers a social-constructivist perspective on social orders that is focused on the dynamics of change. SAFs can be defined as constructed social orders at the mesolevel arising from a shared understanding of the purpose and governing rules of a field. The theory is rooted in institutional theory, network analysis, and Giddens' structuration theory, and builds on Bourdieu's ideas of habitus, field, and capital, as well as on social movement scholarship (Fligstein \& McAdam, 2012/2015, pp. 23-31). It is used to analyse social and political phenomena, including policy fields (Stecker, 2015) and governance processes in energy transitions and urban development (Domaradzka \& Wijkström, 2016; Fuchs \& Hinderer, 2014; Krauss, 2015). By focusing on the dynamics of conflict and change, the theory of SAFs provides concepts to analyse urban actors, their actions, and contexts in complex urban development issues (see Section 2).

To test the explanatory power of the theory, we applied several of its core dimensions in the longitudinal case study of the Utopiastadt Campus, dealing with the contested purpose, planning process, and land development driven by the niche actor Utopiastadt. Drawing on empirical data collected over five years, we aimed to answer three research questions: 
- RQ1: What phases could be distinguished when describing the field of the development at Mirke station following Utopiastadt's arrival in 2011?

- RQ2: How did the interaction between the main actors develop from 2016 and what role did the UCAB as a new governance format play?

- RQ3: How was the new settlement achieved in 2018 and what role did experimentation in the context of the UCAB play in this process?

By answering these research questions, we aim to demonstrate the potential of the social-constructivist theory of SAFs to understand a long-term urban development process and how an episode of experimentation evolved within this process. The objective is to understand the functions of experimentation and whether it contributed to transforming the local governance of city development.

\section{Theory: The Theory of SAFs and its Operationalisation}

As socially constructed orders, stable SAFs rest upon a 'settlement,' which is a shared consensus regarding the purpose, rules, and boundaries of the field. In contrast, contested SAFs are characterised by disagreement about the framing of these elements. Actors who either benefit or are disadvantaged by a settlement are characterised respectively as 'incumbents' or 'challengers' (Fligstein \& McAdam, 2012/2015, Chapter 1). To answer our three research questions, we build upon different core aspects of the original theory.

\subsection{Dynamics of SAFs}

SAFs are either emergent (developing from a previously unformed social space), stable (due to a settlement), or are undergoing an 'episode of contention.' Emphasis is put on the processes through which fields change from one of these states to another and the theory describes these in detail. Typically, destabilisation is brought about by external developments interpreted as threats or opportunities by field actors. This sets off a process of emergent mobilisation, characterised by innovative action and organisational appropriation. If successful, the field is pushed into open contention, marked by shared uncertainty. Stabilisation is achieved through a new settlement. Building on this dynamic, we analyse five phases to provide answers to RQ1 in terms of (1) the original settlement; (2) the onset of contention; (3) the episode of contention; (4) establishment of the new settlement; and finally (5) the characteristics of the new settlement (Fligstein \& McAdam, 2012/2015, pp. 19-23, Chapter 4).

\subsection{Interactions in SAFs}

The theory of SAFs posits that settlements are stabilised through hierarchies and coalitions, or hybrids of both.
These ordering types are characterised by typical practices which, for the purpose of this analysis, we deem to be 'forms of interaction.' Ideal-typically, coalitions are held together by co-operation, while hierarchies rest on advantages gained through competition or coercion, based on the power to harm, withhold resources or threats to do so. We trace the shifting patterns of interactions to answer RQ2. Additionally, we turn to the concepts of 'internal governance units' (IGUs): These bodies, typically institutionalised (e.g., trade associations or compliance units), represent the field towards important stakeholders and provide further crucial functions, thus contributing to field stability and serving the interests of incumbent actors. Moreover, they are often created as part of a settlement and are instrumental to its establishment. To understand the contribution of UCAB from a SAF perspective, we trace the six functions of information, administration, regulation (controlling compliance with mutually-agreed rules), enforcement (forcefully sanctioning rule violations), certification (decisions and rules about who is allowed to be a field actor), and external representation, and include institutionalisation as an additional crucial dynamic (Fligstein \& McAdam, 2012/2015, pp. 13-16, 77-78, 94-96).

\subsection{Explanatory Factors of Dynamics in SAFs}

In both the stabilisation and destabilisation phases of SAFs, three explanatory factors play a crucial role. First, the stability of fields rests largely on the stability of proximate fields within the array of interdependent fields. Second, in constructing, maintaining, and challenging settlements, 'strategic action' (understood as framing and mobilisation) plays a key role. Strategic action is "the attempt by social actors to create and maintain stable social worlds by securing the co-operation of others" (Fligstein \& McAdam, 2011, p. 7) and mainly depends on social skill, understood as the ability to read people and environments and engage interactively with others. Actors rely heavily on strategic action when contesting or crafting a settlement. Finally (at least in modern societies), state actors play a key role in both destabilising and sustaining/ratifying settlements, as they are interested in maintaining stability across a variety of fields (Fligstein \& McAdam, 2012/2015, Chapters 1 and 4). To answer RQ3, we trace these three factors across the identified phases and in their interplay with the UCAB meetings.

\section{Methods and Data}

Our single case study of the Utopiastadt Campus is based on three bodies of data (see Supplementary File): (1) documents of a programmatic nature $(n=8)$ between 2007 and 2018 , laying out the policies, plans, and positions of the main actors regarding the area development; (2) data accumulated from participative observation at meetings from 2015, including field notes (2015-2018), minutes of 
negotiations, and board meetings (2016-2020, $\mathrm{n}=24$ ), as well as the official meeting protocols (2016-2020, $n=17$ ); and (3) five guided interviews (2020) with representatives of the main actors and with the board's external facilitator. The period of study ends in May 2020.

The meeting minutes and protocols, as well as the transcribed interviews, were analysed using qualitative content analysis (Kuckartz, 2018; Mayring \& Fenzl, 2014). Codes were deductively derived from the elements of the theory outlined in Section 2 and data was coded using the program MAXQDA (coding trees and sampling/coding units available upon request). The different bodies of data were used to test and triangulate working hypotheses and the continuously adapted case narrative and flow chart.

\section{Results}

\subsection{RQ1: Phases of the Development of the Area}

Our analysis distinguishes the five phases of the SAF (see Section 2.1). During the phase of the establishment of the settlement, the actors took part in experimentation on communication, decision-making, and planning. An overview of these phases, detailed in the following sub-sections, is given in Figure 1.

\subsubsection{Initial Settlement}

Our case narrative begins in 2011 when Utopiastadt, an aspiring catalyst initiative for bottom-up urban development rooted in the arts and creative scene, as well as civil society, first moved into an old, beautiful, and listed station building (Mirke station) along an abandoned inner-city railway line. At this time, there was a shared consensus between the property owner, the city administration, and the economic development agency that the area around the old railway station should be used and developed as commercial premises. Due to the lack of noise protection from the nearby motorway and a long-term decline in the Wuppertal property market, the area was assessed as being inferior. From a SAF perspective, this situation can be described as a settlement in a spatially central, but relatively neglected, field. The incumbent role was played by the property owner, a nationwide property company with a business strategy of profit-focused section-by-section development.

\subsubsection{Onset of Contention}

Three significant triggers of contention can be identified. First, initiated by local residents, the old railway line was converted into a major inner-city cycle route. This new cycle highway, which opened in 2014/15, delivered significant impetus for the development of areas along its route. Second, Utopiastadt's activities attracted growing public attention at local, regional, and national level. Finally, the property owner decided to push the marketing of its assets in Wuppertal. All three are proximate fields affecting the stability of the field.

Utopiastadt saw the growing desirability of the area as both an opportunity (the possibility of securing a key area of urban development for civil society actors and co-production) and a threat (the possibility of losing this area to conventional investor-driven urban development). It implemented three strategies. First, it singlehandedly expanded its activities to the ground surrounding the station building. Second, it worked on a political-administrative connection between the two fields (station and surrounding premises). A state-funded grant required the initiative to be embedded into an overarching strategy for neighbourhood development.

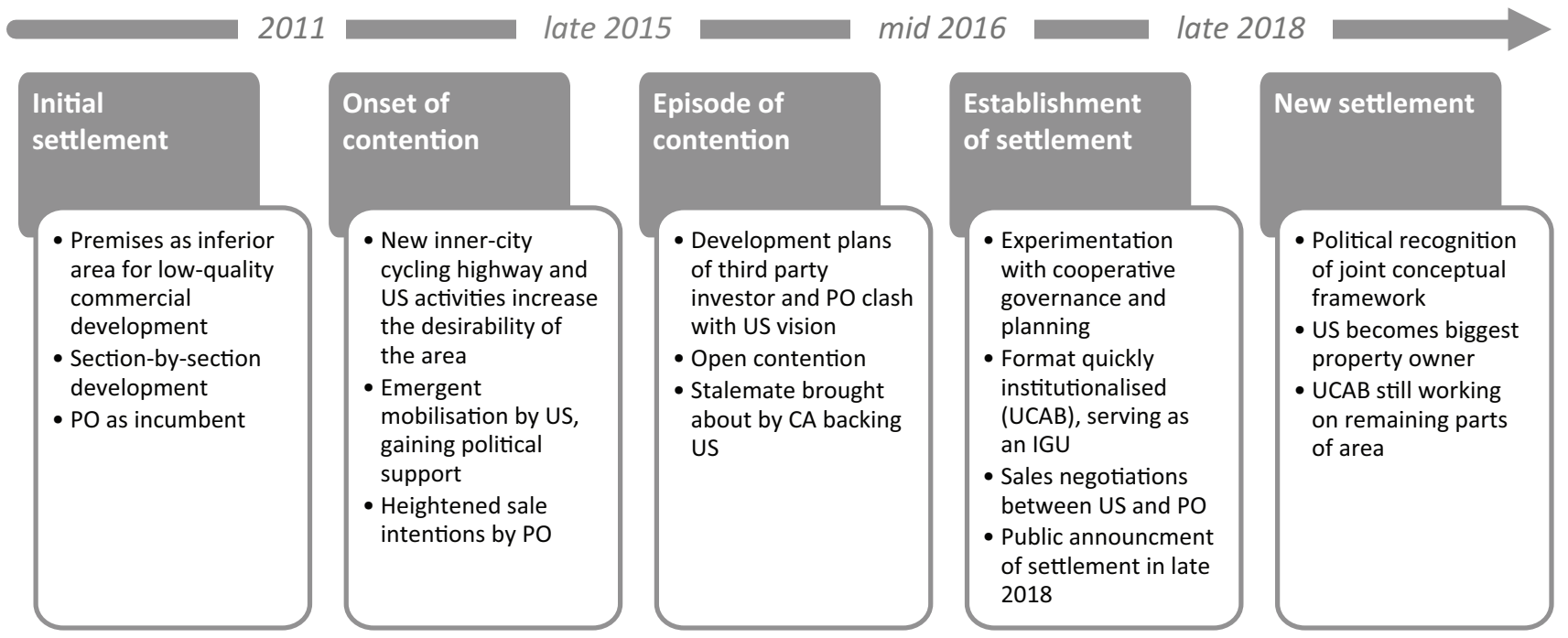

Figure 1. Simplified timeline of the five SAF phases in field changes concerning the area development around Mirke station between 2011 and 2020. Abbreviations: CA = city administration, PO = property owner, US = Utopiastadt (see Supplementary File for a table of the five main actors). 
Utopiastadt, together with a coalition of civil-society actors, participated closely in writing this strategy which was adopted by the city council in October 2014. This 'Integrated Action Programme' (IAP) positioned Utopiastadt as central to the development of the whole area, and Utopiastadt's revival of the station building effectively became a municipal funding project. Finally, Utopiastadt worked towards acquiring the land. In 2015, Utopiastadt's coalition (unsuccessfully) applied for funds from a philanthropic foundation and started a crowdfunding campaign to raise funds and public awareness.

For the property owner, the increasing desirability of the area represented an opportunity for profitable development. Utopiastadt's activities were not perceived as a challenge to the status quo; the company even legitimised Utopiastadt's actions through formal agreements and contracts while simultaneously advancing their own marketing activities. While the property owner initially mobilised within the bounds of the old settlement, in late 2015 they deviated from the strategy of gradual sell-off and delegated the development to a local property developer who proposed a concept for the whole area.

\subsubsection{Episode of Contention}

The choice to delegate the development led to open conflict. In March 2016, a meeting between the local property developer, Utopiastadt, and the city administration, facilitated by the local economic development agency, ended without agreement. Utopiastadt, backed by the city administration, rejected the plans. Subsequently, the developer publicly announced its withdrawal from the project and backed Utopiastadt. Caught off guard, the property owner took the development into their own hands, suggesting a joint process with the city administration. This plan marginalised Utopiastadt, as it included neither a prominent role for Utopiastadt nor a purchase option. It was discussed in two small roundtable meetings, in which both parties called upon the city administration as an ally; in theory, this would only be expected from an incumbent. However, no agreement was reached, and a shared sense of deadlock clearly marked a peak in uncertainty.

The episode took place largely in isolation from the public and the direct influence of proximate non-state fields. Only in one of the meetings with the property owner was Utopiastadt directly supported by an invited representative from 'Forum:Mirke,' a local neighbourhood council institutionalised by the IAP. However, the influence of proximate fields was felt indirectly. On the one hand, in their attempts to secure the administration's support, the different parties tried to frame the prospective impact of the development on local proximate fields such as the housing in the surrounding neighbourhood and the station building itself. Also, the local economic development agency advocated on behalf of commercial development. On the other hand, growing recognition for Utopiastadt among Wuppertal's general public and in the supra-regional urban redevelopment arena created a supportive backdrop that shaped the perspective of the administrative actors and bolstered Utopiastadt's confidence. In terms of power, Utopiastadt's position was clearly dependent on the city administration, as it had no means of imposing its vision for developing the area on its own. However, the property owner also needed the co-operation of the city administration, as there was no zoning in place at the time to support its plans. In the end, the city administration backed up Utopiastadt's position and insisted that the initiative was involved in the development of the area. As will be explained in Section 4.3, this support was largely motivated by having secured the Utopiastadt's project in the station building and its function for the development of the neighbourhood.

\subsubsection{Establishment of New Settlement by Governance} and Planning Experimentation

The resulting stalemate was overcome by a series of externally moderated meetings proposed by the city administration, starting in October 2016. The facilitator was proposed by Utopiastadt and jointly commissioned. This approach developed into a co-operative governance council through which a new settlement was forged in late 2018. It is in this phase that we identify experimentation in the Utopiastadt Campus process. We emphasise that experimentation is not an inherent concept of the theory of SAFs; hence, we draw on urban experimentation theory (as mentioned in the introduction) to analyse the experimental practices. First, the meetings between Utopiastadt, the property owner, the city administration, and later the economic development agency, which had originally been informal in nature, deliberately evolved into an increasingly institutionalised board: the UCAB. Second, co-operation among the members of the UCAB led to consensual practical decisions concerning, for example, infrastructure development, co-ordinated communication with potential buyers, and the approval of a new day-care centre in the area. Third, a collaborative planning process, in which the board members co-operated on a shared understanding of the future development of the area, played a significant role in this phase. In three workshops with external planners (jointly commissioned), the parties produced a joint framework concept, which was adopted by the city council in June 2018. All three elements can be considered experimental as they significantly deviated from the mainstream practices usually present in developing an area owned by a private property owner. We will elaborate on how they contributed towards the transformation of the overall governance setting from a SAF perspective in Sections 4.2 and 4.3.

In parallel, Utopiastadt and the property owner entered into purchase negotiations, resulting in Utopiastadt purchasing significant parts of the area in December 2018 and October 2019. This was largely 
made possible through the acquisition of a major publicly-funded project ('Solar Decathlon Europe [SDE] 2021,' an energy efficient housing competition) and was announced by UCAB at a press conference.

Throughout the process, the municipal actors played an important role as facilitators, mediating with stakeholders and actively participating in UCAB. The property owner also worked actively to facilitate the process, changing its staff and using its own finances to pay for the external moderation and planning experts. As in the preceding episode of contention, the workings of the UCAB took place largely in isolation from the general public. Proximate fields played a more differentiated role. On the one hand, requests from local businesses interested in buying parts of the area put pressure on the UCAB to reach a decision regarding the development of the premises. On the other hand, the ongoing process provided the actors with a means of buying time and effectively shielding the area from influences such as marketing pressure and political discussion. Again, we will take a deeper look at the interplay of these factors and how developments in proximate fields allowed the individual actors to commit to the vision in Sections 4.2 and 4.3.

\subsubsection{New Settlement}

The new consensus manifested itself in three ways. First, the municipality ratified the settlement by officially recognising the joint framework concept in the city council. Second, Utopiastadt gained an incumbent-like status without disadvantaging the property owner: it effectively became the biggest landowner on the site, but the property owner benefited from achieving a normal market price and, in mid-2020, still owned an important part of the land. Third, the actors - for the time being-maintain their commitment to UCAB. Programmatically, the consensus centres on the overall goal of developing the area in line with the activities and values of Utopiastadt, as well as on a co-operative governance model through which the development was facilitated.

\subsection{RQ2: Interaction Forms and the Utopiastadt Campus Area Development Board}

RQ2 focuses on the evolution of the interaction since 2016 and the role of the UCAB as an IGU. We argue that the theory's concept of IGUs provides a useful perspective to understand the emergence of co-operative governance practices, as well as the role these practices played in the development of the overall process. Figure 2 presents a summary.

\subsubsection{Interaction Forms: From Coercion to Competition and Co-Operation}

We analysed the forms of interaction (see Section 2.2) over time based on meeting minutes and identified changing patterns over the different phases:
- Co-operation is the only interaction form present throughout all phases. It plays a vital role in the contention phase, signifying support for Utopiastadt in the face of contention. Co-operation is the defining and constant interaction form during the establishment of the new settlement, reflecting the trust and respect developed between all participants.

- Competition is most frequent in the contention phase, but also present in the UCAB-mainly due to an ongoing struggle for interpretative power between Utopiastadt and the property owner. Significantly, in some meetings before and after the main settlement, disputes arose over programmatic differences regarding residential construction.

- Coercion in our case study only occurs in the form of threats to use certain forms of power (financial, protest, etc.) or to withhold important resources. Codings here were notably fewer but must be heavily weighted because coercion potentially puts current and future relationships at risk. Coercion was mostly used in the contention phase to test red lines, or to call upon or provocatively challenge the hierarchy. Notably, the frequency reduces with the establishment of the UCAB and no instances of coercion occurred after the adoption of the new settlement, which fits with the shift in roles and the fact that no party suffered 'severe losses.'

We found that the new settlement went hand in hand with a shift towards co-operation, indicating a more coalition-like relationship between the actors.

4.2.2. IGU: Structures, Rules, and Functions in the Phase of the Governance and Planning Experimentation

Based on an analysis of the official meeting protocols and minutes, we assess the extent to which the UCAB took on the characteristics of an IGU (see Section 2.2). The board did not fulfil all functions at all times, but this is not a prerequisite for an IGU to work:

- Institutionalisation: The group quickly institutionalised itself by agreeing on a name, a regular format, and a clear objective. Since the new settlement, the group meetings have continued, albeit on a more infrequent and ad-hoc basis and with uncertainty about the future commitment and composition.

- Administration: This function was quickly and effectively fulfilled primarily by appointing an external facilitator and adopting co-ordinated protocols.

- Information: Exclusive, new, and/or relevant information was exchanged openly in nearly all meetings and by all members to provide grounds for mutual agreements. 
Category $\quad$ Columns structured by meetings ( $\mathrm{n}=27$ ). All meetings were non-public, except meeting 25 which was a joint press conference.

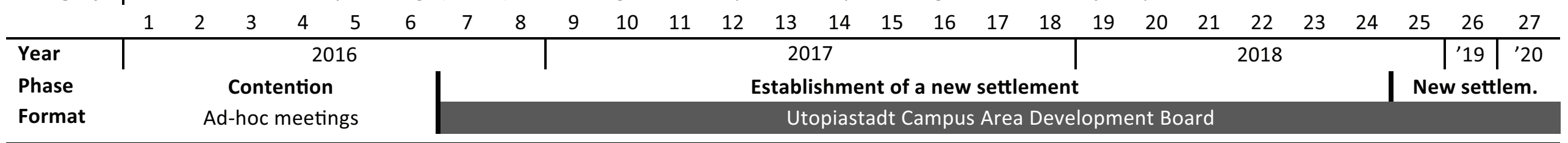

Actors Participation in meetings: grey line = participation with at least one representative; no line = no representative at meeting

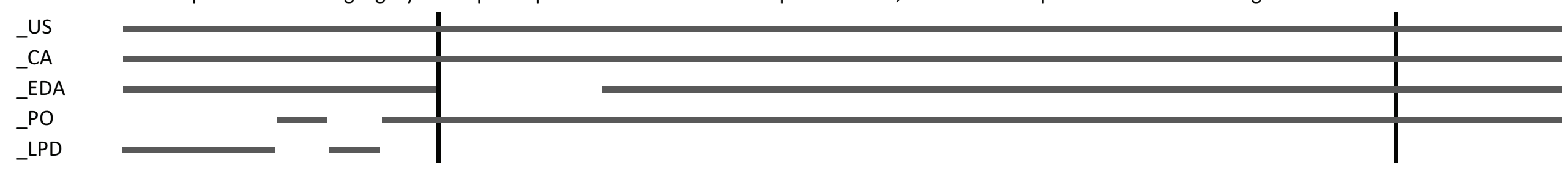

IntForm Analysis based on IF codings $(n=163)$ in own meetings notes; rounded average across all meetings $($ by the line): Coop. $=3(n=69)$, Comp. $=2(n=68)$, Coerc. $=1,(n=25)$; smallest dot $\bullet=$ IF coded less than average; middle $\bullet=$ average; big dot $\bigcirc=$ more than average; very big dot $=$ more than $2 \sigma$

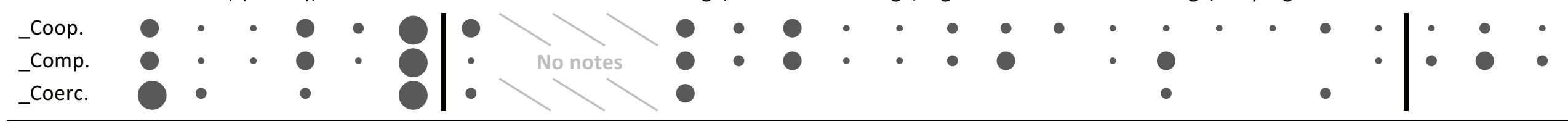

IGU Analysis based on protocols and minutes; white = no hint/does not apply; light grey = applies to a certain degree; dark grey = fully applies

_Instit.

Admin.

_Info

_Regul.

Ad-hoc meetings

Enforce.

_Certif.

_ExtRep.

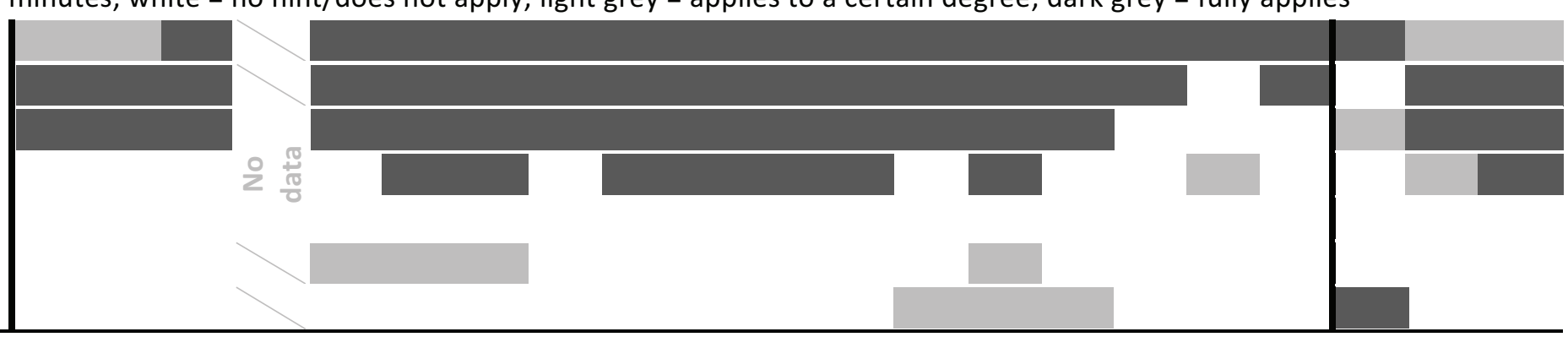

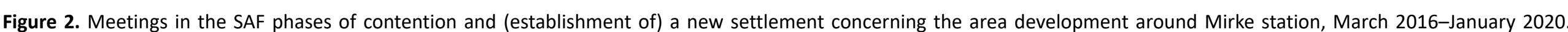

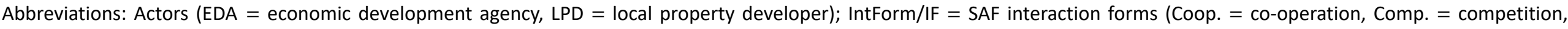

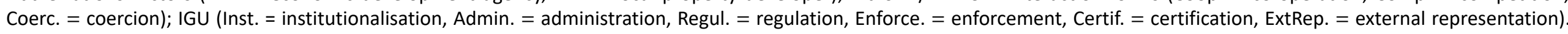
Thick black vertical lines highlight the different phases (see Section 4.1). 
- Regulation: Mutually-agreed rules were frequently discussed and at times referred to in the meetings.

- Enforcement: No occurrences were found, as there were no attempts to openly question the rules put in place by the board.

- Certification: The board defined criteria for potential buyers and businesses. In separate meetings, interested companies had to demonstrate their suitability. Consensual decisions led to the acceptance of one applicant (the day-care centre).

- External representation: On several occasions, the UCAB acted as a unified representative for the stakeholders, specifically in terms of the framework concept and at the joint press conference signalling the new agreement. Also, the decision makers from all the parties involved were regularly informed about the work and progress of the UCAB, which built trust in the construct.

In essence, while the UCAB's original motivation was to overcome the stalemate between the competing development models, it quickly took on the characteristics of an IGU, carrying out many functions and contributing to the overall stabilisation of co-operative practices and, finally, the settlement.

\subsection{RQ3: Enabling Factors of the Process and the Role of Governance Experimentation}

To answer RQ3, we traced the three main influencing factors identified by the theory of SAFs-strategic action, state actors, and proximate fields-over the flow of events. As UCAB was crucial for the new settlement, we also accounted for its specific role. Figure 3 presents this information in a simplified, complexity-reduced graph. Overall, the process was made possible by the interplay of the three major factors. We illustrate this by highlighting five significant steps:

1. Increased desirability: The initial increase in desirability of the area can be traced to two bottomup urban development projects-the inner-city cycling lane, which positively affected several areas along its route, and the Utopiastadt's original project to revive Mirke station. From a SAF perspective, both are proximate fields.

2. Emergent mobilisation by Utopiastadt: Emergent mobilisation can largely be analysed in terms of strategic action by Utopiastadt. Through networking, the weaving of narratives and strategic navigation of the funding and policy landscape, the initiative attracted support. The IAP connecting the project to the municipal urban redevelopment agenda was crucial. The IAP would not have been possible without the support of the city administration (state actors), which was interested in securing funding for Utopiastadt's revival of Mirke station. This interest was rooted in a concern for the surrounding urban area, which had already been on the redevelopment agenda but was only identified as the distinct neighbourhood 'Mirke' through the IAP. The architectural restoration and social revival of the station building was seen as a central lever for the revival of the neighbourhood. The IAP provided the necessary legal framework for supporting this restoration, as outlined in Section 4.2. In this way, Utopiastadt's project in the Mirke station building was closely tied to two proximate fields, which strongly influenced the administration in the subsequent process.

3. Stalemate: The disagreement was largely a consequence of Utopiastadt's and the property owner's divergent strategies. However, the stalemate can be traced to strong support for the initiative from the municipality (state actors) and to Utopiastadt's refusal to accept the marginalised role offered in the company's plans (strategic action). Both were influenced by proximate fields: The municipality was motivated to back the Mirke station project and to secure the integrated development of the neighbourhood. Additionally, Utopiastadt received strong support from the local community, as well as increased supra-regional recognition, which influenced both the municipality's position and Utopiastadt's self-confidence.

4. (First) moderated meetings: The meetings were made possible due to the strategic decision of all actors to adopt a governance mode in which moderation and a prolonged timeframe could reconcile the interests (strategic action). Again, the city administration (state actors) played a major part in facilitating these meetings. However, the property owner also made a significant contribution by changing their strategy for the area, adopting a longer timeframe, and withdrawing a particularly hawkish representative. The remaining staff agreed to pay for the moderation and planning offices (strategic action)-a decision based on earlier experiences from other projects (proximate fields).

5. Purchase negotiations: The purchase negotiations reconciled the property owner's aim of profitable development with Utopiastadt's aim of securing the area. UCAB made the negotiations possible through combining elements. The tangible topics dealt with served as boundary objects around which trust grew. This trust enabled the negotiations, but their success hinged on Utopiastadt's ability to pay market prices. Utopiastadt achieved this by strategic action: while UCAB was in operation, it forged a coalition from local foundations, businesses, and the University of Wuppertal, which organised financial support and funding. Here, proximate fields played a major enabling role. First, the depressed Wuppertal property market meant the market price was relatively low. 


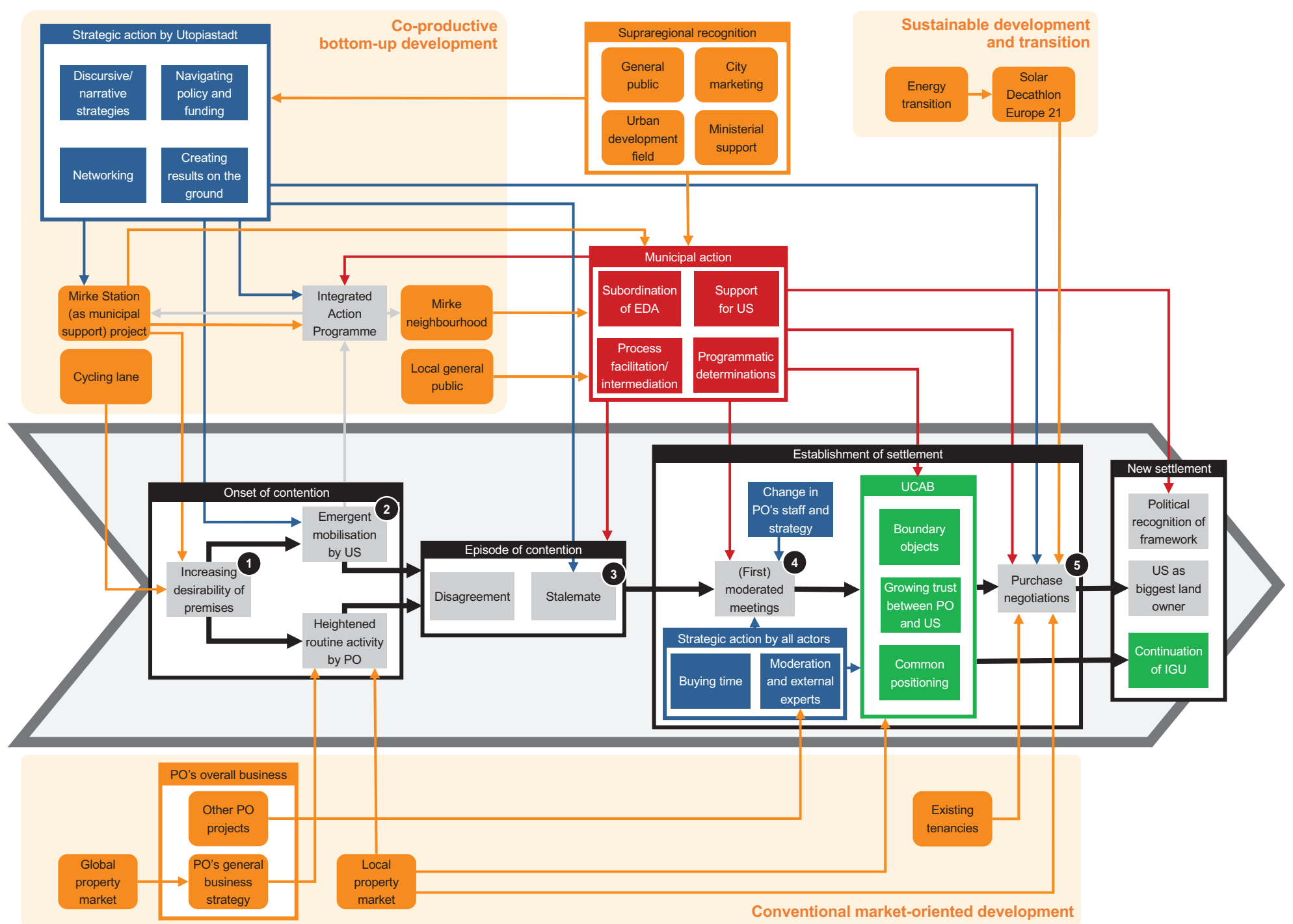

Figure 3. Interplay of influencing factors in the process of the SAF. Nodes: grey = processual flow of events; coloured $=$ types of influencing factors. Arrows: black $=$ processual flow of events, grey $=$ processual flow branching off from main process with significant feedback influence, coloured $=$ influencing factors, big background arrow $=$ indicating flow for convenience. Boxes: summaries for readability, thick frames $=$ similar types with headline, faded background $=$ thematic. Colours: blue $=$ strategic action, red $=$ state actors, orange $=$ proximate fields, green $=$ UCAB. Numbers: focal steps of analysis. 
Second, existing tenancies on the premises provided a steady income stream. Third, Utopiastadt's coalition acquired the project SDE 2021, which was expected to provide income in the coming years. The existing tenancies and the SDE are both subordinate SAFs, with the SDE also rooted in the broader energy transitions field. The final factor was the municipality, which actively participated in the programmatic process of UCAB (thereby excluding housing development, which would have warranted higher market prices) and-by intervention of the Lord Mayorcreated the ultimate trust needed for the acquisition (state actors).

As this outline highlights, strategic action, facilitation by state actors, and the field environment were individually necessary but only jointly-and in their interplaysufficient. Proximate fields provided both an enabling and restricting environment for the development of the SAF. In Figure 3, we summarise these supportive fields under the themes of co-productive bottom-up development, supra-regional recognition, and sustainable development and transition. Fields summarised under conventional market-oriented development played a more restricting role in our case. However, our analysis also shows that strategic action was necessary to exploit these influences. Proximate fields were also a major motivation for the actions of the state actors. Finally, our analysis shows that the establishment and work of the IGU was an integral part of this interplay. First, the work of UCAB was made possible and shaped by the three analysed factors. Second, UCAB became an enabling factor for the settlement itself, and co-operative routines continued after our analysis period (see Section 4.2). This, again, fits with the assumptions of the theory, which posits that IGUs are often put in place to facilitate and stabilise original settlements in emergent SAFs. Third, our analysis also sheds light on how the IGU (apart from stabilising co-operation) contributed to the settlement, as shared boundary objects, increased trust and common positioning proved to be necessary conditions for the acquisition.

In this light, how does the phase of experimental planning and its product, the joint framework concept, fit into the SAF analysis? As the interviewees stated, the material results of planning in the framework were not as significant as the process itself. On the one hand, the planning process became a major boundary object for $U C A B$, enabling the growth of trust and co-operation. On the other hand, it provided an overall storyline for the work of the council, both providing assurance that the actors were 'on track' internally and justifying UCAB's work with the municipal organisations and the property owner. In this way, the planning process enabled the IGU to function long enough to create the conditions necessary for the settlement itself.

\section{Discussion}

\subsection{The Theory of SAFs and Urban Experimentation}

We used the theory of SAFs to describe and explain a process of area development in a German city and to assess its explanatory power regarding the conditions and outcome of an altered governance process that encompassed practices of experimentation.

We show that the theory is useful to unpick and analyse contested area development processes and perspectives. The notions of co-operation, competition, and coercion as central forms of interaction proved to be instrumental for detecting changes in the communication style, and clearly marked the onset of the co-operative planning phase. We traced the establishment and functioning of an IGU, which helped to explain why and how an agreement was reached in a new governance mode. Furthermore, the three SAF concepts of influence of proximate fields, strategic action, and state interventions contributed towards explaining the process. Taken together, we showed that the theory can help to illuminate the emergence and function of experimentation in its wider governance context.

However, the theory of SAFs does have shortcomings when analysing urban experimentation. First, from a SAF perspective, state actors primarily hold regulatory power and intervene in non-state fields in a top-down manner. On the one hand, we observed such dynamics when the city administration used its regulatory power to block the property owner's development ideas. On the other hand, administrative actors engaged at eye level and provided continuous programmatic orientation, which contributed towards reaching a common position. This space for manoeuvre for state actors is vital to instigate and allows for the emergence of collaborative planning modes and experimentation.

Second, the meso-level construction of SAFs offers few conceptual tools to analyse the specific dynamics and behaviour of individual actors at micro-level; particularly for operationalising strategic action and social skill. Our analysis, therefore, had to inductively derive the strategic actions described in Section 4.3. It could be worth analysing strategic action with concepts from narrative analysis, micro-sociological theory, and typologies on discursive policy-making as the one put forward by Leipold and Winkel (2017).

Third, we came to focus on important turning points in the course of events and analysed the influences and contexts of these moments. In the theory, decisive moments are reflected in the notion of (external) shocks, leading to the destabilisation of fields. These shocks resonate with recent conceptualisations in social innovation research about "critical turning points" (Pel et al., 2017). We suggest that the dynamics around these decisive moments, not only in terms of destabilising but also re-establishing the stability of fields, should be further explored. 
Finally, the theory of SAFs does not explicitly refer to notions such as experimentation or experiments. On a very general level, experimentation could be conceptualised as a form of strategic action through which the actors in the case tried to overcome the stalemate that could not be overcome by adhering to the conventional practices of area development. Furthermore, the theory offers the concept of 'innovative action,' referring to "actors violating field rules with respect to acceptable practices and engaging in innovative action in defence or support of group interests" (Fligstein \& McAdam, 2011, p. 9). These innovative actions are supposed to be taken by 'challengers,' or actors considered as "sensing an opportunity to advance their position in the field through novel means" (Fligstein \& McAdam, 2011, p. 10). Instead of challenging existing coalitions and action, incumbents are supposed to assure the status quo in the field in order to stabilise the situation (Fligstein \& McAdam, 2011). These distinct actions by certain actors in the theory resonate with the distinctions made between activities conducted by (innovative) niche actors and regime incumbents in transition theory (Geels, 2012). Moreover, the notion of innovative action may suggest linkages to ideas revolving around the concept of (urban) experimentation, meanwhile established in transition theory (Fuenfschilling, Frantzeskaki, \& Coenen, 2019). However, a deeper conceptual debate around these concepts is beyond the scope of this work. We suggest that future research could explore the conceptual distinctions and conjunctions between innovative action from the theory of SAFs and (urban) experimentation. This may help to describe the nestedness and interaction effects of urban experimentation within SAFs beyond a single in-depth case study.

\subsection{The Development of the Utopiastadt Campus as an Example of Experimentation and Collaborative Planning?}

As we demonstrated, laying the foundations for the Campus was made possible by involving all four actors in a changed pattern of interaction and communication, working on a joint framework concept, and building trust for the purchase negotiations. As shown, this was possible through the interplay of influential proximate fields, strategic action and changed strategies (mainly by the property owner), and intervention by the state actors. However, whether the process is a good example of urban experimentation and collaborative planning is debatable.

Concerning experiments, we listed central criteria for such experiments in the introduction: Urban experiments are defined as situations where a multistakeholder, multi-disciplinary actor group deliberately decides to jointly deviate from the status quo, to enter a phase and setting of trial and error, and is eager and willing to learn from it in the longer run or even set up stand-alone platforms for urban experiments (like city labs). Concerning collaborative planning, Innes and Booher (2018) present three normative aspects of collaborative planning: (1) The planning process should enable individual and collective capacity-building among the participants, beyond specific outcomes or solutions; (2) the open character of the planning process must be guaranteed-no pseudo-transparent and pre-determined processes are allowed; and (3) the collaborative planning process should include-at least with a certain possibility-contributions to make institutions more effective, adaptive, and resilient to deal with complexity.

Accordingly, both concepts ideally demand the deliberate creation of a safe space for interaction and a joint and open-ended learning environment. In our case, it should be noted that the process was not a joint endeavour to explicitly explore and modify area development processes in Wuppertal and beyond; it was, in fact, an attempt to resolve a specific clash of interests. The actors' decisions to participate in the UCAB meetings and to change the governance mode can be interpreted as individual strategic choices in an attempt to secure the objectives of their respective organisations. The purchase deal was mostly made possible by the acquired and acknowledged strategic and economic power of Utopiastadt, not by the property owner's support for the experimental and participatory nature of the development. It is questionable whether the Mirke case had any short-term influence on the property owner's business model. The perspectives of the representatives in the meetings and the interview showed that the changed procedure was seen as a symbol of adaptive management-and the case itself was perceived as an exception to the rule. At city level, the interpretations were mixed: Some saw the deal as a specific action to support and protect the Utopiastadt project, while others perceived it as an example of changing planning culture and identified need for more collaborative and participatory not-for-profit city development projects. On the whole, in respect of idealtype urban experiments and collaborative planning, this highlights why we consider it appropriate to speak only of an episode of experimentation and collaboration.

However, seen in the broader context of cultural changes in urban planning, the process provided all actors with important learning opportunities. The process was-to a certain extent-open-ended and transparent, and the decisions were based on consensus. We could also clearly trace individual learning processes in the data: The actors were able and willing to listen to the arguments and perspectives of the others involved. Over time, they all learned to see the potential development of the area through the lens of the other actors and sometimes even swapped roles by explaining or defending the others' standpoints to outsiders or newcomers. All the actors recognised the importance and the uniqueness of jointly publishing the framework concept and featuring all the logos on the front cover. Even if the experimental process evolved stepby-step over time, the concrete planning and urban 
development results are profound. It could, therefore, be argued that these organically evolving, unintended episodes of experimentation and collaboration harbour at least as much potential for change in urban governance strategies and culture as intentional experiments. However, further research is needed-both in our case and in other projects - to trace the long-term impact of the seeds that have been sown and the real-world experiences that have been gained.

\section{Conclusion}

In our article we have described and analysed an urban process with an experimental and collaborative episode in an inner-city area development. From a normative perspective of collaborative planning and urban experimentation, the process may not have ticked all the boxes. Nevertheless, the outcome of the process can be deemed a success story for unconventional and adaptive planning processes and can be recognised as a fruitful learning environment. Applying the theory of SAFs to this case proved to be instrumental for analysing and understanding the context and determining factors of such non-ideal but real-world urban governance processes and episodes of experimentation. The theory helps particularly to understand the specific configuration of (proximate) fields, actors' vested interests in these fields, and the power struggles between interpretations, process sovereignty, and development objectives. It also helps to understand the emergence of episodes or settings of experimentation as a shift in a wider governance context. Our case shows how and why experimentation can fulfil important functions of finding new settlements in contested fields. By using the theory of SAFs, we hope to have contributed to opening up novel perspectives on the inherent process dynamics at play in urban experimentation and collaboration that could transform governance cultures. In turn, this may help to inform scientific scholars and practitioners dealing with urban transformations and experimentation in other socio-spatial contexts.

Postscript: After the end of the study period, the remaining area was purchased by a private person at the end of 2020. This was done in coordination with Utopiastadt and the city of Wuppertal and is intended to reserve this space for the further development of the Utopiastadt Campus. The PO thus no longer owns any part of the former railway grounds.

\section{Acknowledgments}

We would like to thank the handling editors of the thematic issue of Urban Planning and two anonymous reviewers for their very helpful comments. We thank all the actors for supporting our research and allowing us access to all meetings and documents. The empirical work was partly funded by the framework programme
'Research for Sustainable Development (FONA)' of the German Federal Ministry of Education and Research (BMBF). M.W. worked in the 'Well-Being Transformation Wuppertal' project (Grant No. 01UT1412A) from 2015 to 2018 and has held a doctoral scholarship from the Heinrich Böll Foundation since 2018. B.B. works in the Junior Research Group in Social-Ecological Research 'UrbanUp-Upscaling Strategies for an Urban Sharing Society' (Grant No. 01UU1701A). M.W. conducted the long-standing accompanying research, developed the experimentation lens on the USC process, and led the writing and revision process. B.B. contributed the SAF perspective on governance. M.W. and B.B. jointly operationalised the theory to the case, conducted the interviews, performed the empirical analyses, and arranged the results. T.v.W. contributed to the development of the main arguments and to the writing of the article.

\section{Conflict of Interests}

The authors declare no conflict of interests.

\section{Supplementary Material}

Supplementary material for this article is available online in the format provided by the author (unedited).

\section{References}

Åström, J. (2020). Participatory urban planning: What would make planners trust the citizens? Urban Planning, 5(2), 84-93. https://doi.org/10.17645/up.v5i2. 3021

Bernstein, S., \& Hoffmann, M. (2018). The politics of decarbonization and the catalytic impact of subnational climate experiments. Policy Sciences, 51(2), 189-211. https://doi.org/10.1007/s11077018-9314-8

Bulkeley, H., \& Castán Broto, V. (2013). Government by experiment? Global cities and the governing of climate change. Transactions of the Institute of British Geographers, 38(3), 361-375. https://doi.org/ 10.1111/j.1475-5661.2012.00535.x

Bulkeley, H., Marvin, S., Palgan, Y. V., McCormick, K., Breitfuss-Loidl, M., Mai, L., . . . Frantzeskaki, N. (2019). Urban living laboratories: Conducting the experimental city? European Urban and Regional Studies, 26(4), 317-335. https://doi.org/10.1177/ 0969776418787222

Domaradzka, A., \& Wijkström, F. (2016). Game of the city re-negotiated: The polish urban re-generation movement as an emerging actor in a strategic action field. Polish Sociological Review, 2016(195), 291-308.

Evans, J., Karvonen, A., \& Raven, R. (2016). The experimental city: New modes and prospects of urban transformation. In J. Evans, A. Karvonen, \& R. Raven (Eds.), The experimental city (pp. 1-12). London: Routledge. 
Fligstein, N., \& McAdam, D. (2011). Toward a general theory of strategic action fields. Sociological Theory, 29(1), 1-26. https://doi.org/10.1111/j.14679558.2010.01385.x

Fligstein, N., \& McAdam, D. (2015). A theory of fields (First issued as an Oxford University Press paperback). Oxford, Auckland, and New York, NY: Oxford University Press. (Original work published 2012)

Forester, J. (1999). The deliberative practitioner: Encouraging participatory planning processes. Cambridge, MA: MIT Press.

Fuchs, G., \& Hinderer, N. (2014). Situative governance and energy transitions in a spatial context: Case studies from Germany. Energy, Sustainability and Society, 4(1). https://doi.org/10.1186/s13705-014-0016-6

Fuenfschilling, L., Frantzeskaki, N., \& Coenen, L. (2019). Urban experimentation \& sustainability transitions. European Planning Studies, 27(2), 219-228. https:// doi.org/10.1080/09654313.2018.1532977

Geels, F. W. (2012). A socio-technical analysis of lowcarbon transitions: Introducing the multi-level perspective into transport studies. Journal of Transport Geography, 24, 471-482. https://doi.org/10.1016/ j.jtrangeo.2012.01.021

Healey, P. (1997). Collaborative planning: Shaping places in fragmented societies. Vancouver: UBC Press.

Healey, P. (2004). Creativity and urban governance. Policy Studies, 25(2), 87-102. https://doi.org/10.1080/ 0144287042000262189

Healey, P. (2006). Collaborative planning: Shaping places in fragmented societies (2nd ed.). Basingstoke and New York, NY: Palgrave Macmillan.

Innes, J. E. (1995). Planning theory's emerging paradigm: Communicative action and interactive practice. Journal of Planning Education and Research, 14(3), 183-189. https://doi.org/10.1177/ $0739456 \times 9501400307$

Innes, J. E., \& Booher, D. E. (2018). Planning with complexity: An introduction to collaborative rationality for public policy (2nd ed.). London and New York, NY: Routledge.

JPI Urban Europe. (2019). Strategic research and innovation agenda 2.0. Brussels: Joint Programming Initiative Urban Europe.

Krauss, G. (2015). The creation of a second centre pompidou in metz: Social embedding of a new regional cultural facility and formation of a strategic action field. European Planning Studies, 23(8), 1494-1510. https://doi.org/10.1080/09654313.2013.817542

Kronsell, A., \& Mukhtar-Landgren, D. (2018). Experimental governance: The role of municipalities in urban living labs. European Planning Studies, 26(5), 988-1007. https://doi.org/10.1080/09654313.2018.1435631

Kuckartz, U. (2018). Qualitative Inhaltsanalyse: Methoden, Praxis, Computerunterstützung [Qualitative content analysis: Methods, practice and using software]. Weinheim and Basel: Beltz Juventa.

Leipold, S., \& Winkel, G. (2017). Discursive agency:
(Re-)conceptualizing actors and practices in the analysis of discursive policymaking. Policy Studies Journal, 45(3), 510-534. https://doi.org/10.1111/psj. 12172

Mayring, P., \& Fenzl, T. (2014). Qualitative Inhaltsanalyse [Qualitative content analysis]. In N. Baur \& J. Blasius (Eds.), Handbuch Methoden der empirischen Sozialforschung [Handbook of methods of empirical social research]. (pp. 543-556). Wiesbaden: Springer Fachmedien Wiesbaden. https://doi.org/ 10.1007/978-3-531-18939-0_38

Nevens, F., Frantzeskaki, N., Gorissen, L., \& Loorbach, D. (2013). Urban transition labs: Co-creating transformative action for sustainable cities. Journal of Cleaner Production, 50, 111-122. https://doi.org/ 10.1016/j.jclepro.2012.12.001

Pel, B., Bauler, T., Avelino, F., Backhaus, J., Ruijsink, S., Rach, S., . . . Kemp, R. (2017). The Critical Turning Points database; concept, methodology and dataset of an international Transformative Social Innovation comparison (TRANSIT Working Paper No. 10). Brussels: TRANSIT.

Scholl, C., \& Kemp, R. (2016). City labs as vehicles for innovation in urban planning processes. Urban Planning, 1(4), 89-102. https://doi.org/10.17645/up.v1i4.749

Sengers, F., Wieczorek, A. J., \& Raven, R. (2016). Experimenting for sustainability transitions: A systematic literature review. Technological Forecasting and Social Change, 145, 153-164. https://doi.org/10.1016/ j.techfore.2016.08.031

Seyfang, G., \& Haxeltine, A. (2012). Growing grassroots innovations: Exploring the role of community-based initiatives in governing sustainable energy transitions. Environment and Planning C: Government and Policy, 30(3), 381-400. https://doi.org/10.1068/ c10222

Staffans, A., Kahila-Tani, M., \& Kyttä, M. (2020). Participatory urban planning in the digital era. In S. Geertman \& J. Stillwell (Eds.), Handbook of planning support science (pp. 307-323). Northampton: Edward Elgar Publishing.

Stecker, R. (2015). Zur Entstehung des neuen Politikfeldes Klimawandelanpassungspolitik in Deutschland [On the emergence of the new policy field of climate change adaptation policy in Germany]. Der Moderne Staat: Zeitschrift für Public Policy, Recht und Management, 8(1), 71-89. https://doi.org/10.3224/dms. v8i1.19111

Torrens, J., Schot, J., Raven, R., \& Johnstone, P. (2019). Seedbeds, harbours, and battlegrounds: On the origins of favourable environments for urban experimentation with sustainability. Environmental Innovation and Societal Transitions, 31, 211-232. https:// doi.org/10.1016/j.eist.2018.11.003

UN. (2016). New Urban Agenda: Quito declaration on sustainable cities and human settlements for all. New York, NY: United Nations.

von Wirth, T., Fuenfschilling, L., Frantzeskaki, N., \& 
Coenen, L. (2018). Impacts of urban living labs on sustainability transitions: Mechanisms and strategies for systemic change through experimentation. European Planning Studies, 27(2), 229-257. https://doi.org/ 10.1080/09654313.2018.1504895

Voytenko, Y., McCormick, K., Evans, J., \& Schliwa, G. (2016). Urban living labs for sustainability and low carbon cities in Europe: Towards a research agenda. Journal of Cleaner Production, 123, 45-54. https:// doi.org/10.1016/j.jclepro.2015.08.053

WBGU. (2016). Humanity on the move: Unlocking the transformative power of cities-Flagship report. Berlin: WBGU.

Willinger, S. (2014). Governance des Informellen: Planungstheoretische Überlegungen [Governance of the informal: Planning theoretical reflections]. Informationen zur Raumentwicklung, 2/2014, 147-156.

\section{About the Authors}

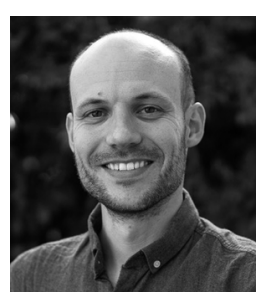

Matthias Wanner holds a degree in Psychology and Political Studies. He is a Research Fellow at the Wuppertal Institute, member of the Centre for Transformation Research and Sustainability (transzent), and a Doctoral Student at Leuphana University's Faculty of Sustainability. His areas of research include transdisciplinary and transformative research in real-world laboratories, transformative learning, and bottom-up approaches of societal and urban change.

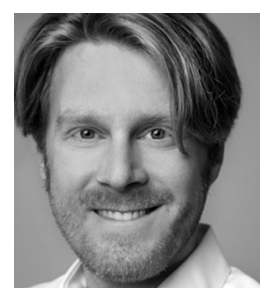

Boris Bachmann is a Research Fellow and PhD Candidate at the Centre for Transformation Research and Sustainability (transzent) as well as at the School of Human and Social Sciences at the University of Wuppertal. As a member of the Junior Research Group 'UrbanUp,' his doctoral research focuses on the transformative potential of bottom-up "city makers" in the governance of urban development. He holds a Master's degree in Political Sciences from the University of Bonn.

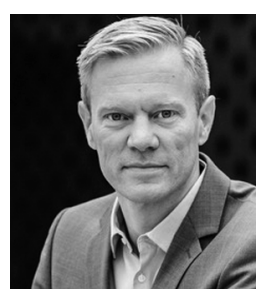

Timo von Wirth is currently Assistant Professor at the Dutch Research Institute for Transitions within the Erasmus School of Social and Behavioral Sciences. He serves as the Project Lead for several EU research projects, and his research focuses on transition dynamics and co-creation in environmental governance as well as on local identity, urban experimentation, and the role of place for human well-being. 